Journal of Advanced Research in Fluid Mechanics and Thermal Sciences

Journal homepage: www.akademiabaru.com/arfmts.html ISSN: 2289-7879

\title{
Oil Palm Empty Fruit Bunches (EFB): Influence of Alkali and Acid Treatment on the Mechanical Properties of Medium Density Fibreboard (MDF)
}

\author{
Zawawi Ibrahim ${ }^{1,}{ }^{*}$, Mansur Ahmad², Astimar Abdul Aziz ${ }^{1}$, Ridzuan Ramli', Noorshamsiana Abdul \\ Wahab $^{1}$, Aisyah Humaira Alias ${ }^{3}$, Syaiful Osman ${ }^{2}$, Ewe Lay Sheng ${ }^{4}$ \\ 1 Malaysian Palm Oil Board (MPOB), Biomass Technology Unit, Engineering and Processing Division, Jalan Sekolah, Pekan Bangi Lama, 43000 \\ Kajang, Selangor, Malaysia \\ 2 Faculty of Applied Sciences, Universiti Teknologi MARA, 40400 Shah Alam, Selangor, Malaysia \\ 3 Institute of Tropical Forestry and Forest product (INTROP), Universiti Putra Malaysia, 43400 Serdang, Selangor, Malaysia \\ 4 College of Engineering, Universiti Tenaga Nasional, Jalan IKRAM-UNITEN, 43000 Kajang, Selangor, Malaysia
}

\section{ARTICLE INFO}

\section{Article history:}

Received 28 January 2020

Received in revised form 12 July 2020

Accepted 13 July 2020

Available online 17 December 2020

\section{Keywords:}

Empty Fruit Bunches (EFB); Sodium Hydroxide ( $\mathrm{NaOH}$ ); Acetic Acid; Bending Strength; Internal Bonding

\section{ABSTRACT}

Empty Fruit Bunches (EFB) are abundance residues from palm oil plantation was recognised as a potential material for manufacture such as particleboard and medium density fibreboard (MDF). The objective of this study is to identify and assess the potential effects of chemical treatment and concentration on the mechanical and bonding properties of MDF from EFB oil palm fibres. The EFB fibres were treated at 0.2 , $0.4,0.6$ and $0.8 \%$ of sodium hydroxide $(\mathrm{NaOH})$ and acetic acid $\left(\mathrm{CH}_{3} \mathrm{COOH}\right)$, and the fibres were used in the MDF production. Mechanical test included modulus of rupture (MOR), modulus of elasticity (MOE) and internal bonding (IB) were conducted. Between the chemical treatment and the concentration, the chemical types used had a more prominent effect compared to the concentration. This study also shows that both treatments resulted in different MDF performance, where acid acetic fibre produced better bending and bonding properties. The optimum condition was $0.4 \%$ for $\mathrm{NaOH}$ and $0.6 \%$ for $\mathrm{CH}_{3} \mathrm{COOH}$ to produced panels with good strength and better dimensional stability. Such sample for $0.4 \% \mathrm{NaOH}$ had $17.9 \mathrm{MPa}, 1297 \mathrm{MPa}$ and 0.48 $\mathrm{MPa}$, and for $0.6 \% \mathrm{CH}_{3} \mathrm{COOH}$ had $22.1 \mathrm{MPa}, 1641 \mathrm{MPa}$ and $0.56 \mathrm{MPa}$, for MOR, MOE and IB, respectively.

\section{Introduction}

Medium density fiberboard (MDF) is one of the largest wood-based industry in Malaysia. Normally, the MDF industry uses rubberwood, acacia wood and mixed hardwood to produce MDF.

\footnotetext{
* Corresponding author.

E-mail address: zawawi@mpob.gov.my
}

https://doi.org/10.37934/arfmts.79.1.4453 
Due to the lack of wood and the tendency to use lignocellulosic sources as fiber materials, natural fibers have been identified as a potential source for the MDF industry. Natural fibre uses in the composite industry are widely used because of their availability and strength properties. An empty fruit bunch (EFB), as being one of the world's largest producers of palm oil, could be utilised by the composite sector as a fibrous raw material. Oil palm empty fruit bunch (EFB) are the most used for composite materials among others oil palm fibers include the trunk and frond. Several studies showed that EFB fibers can be utilized such as in the production of polymer composite, particleboard, fiberboard, and fuels [1-5].

However, the EFB fibers have several disadvantages include high oil content, contains waxy layer on the fiber surface and have alkaline $\mathrm{pH}$. Poor physical and mechanical properties would be caused by the EFB 's properties. Thus, the treatment of EFB fibers is essential to overcome the unfavorable properties of producing fibers with matrix-compatible properties, especially in composite production. Numerous research and studies have been conducted in relation to the treatment of EFB fibers [6-11]. In addition, several types of chemicals, such as silane, succinic anhydride, acrylic acid, formic acid, and phosphoric acid, are also used for the treatment of EFB fibers [9-13].

The modification of EFB fibers treated with acetic and propionic anhydride has been shown to increase the bonding strength of MDF. Such research was carried out by Khalil et al., [14] and they found that the cause for the increase was due to better compatibility between the matrix resin surfaces. The modification enhanced the internal bonding (IB) as the hydrophobic properties of the fiber surface were increased. Pan et al., [15] on the other hand, found that $\mathrm{CH}_{3} \mathrm{COOH}$ treatment lowers the $\mathrm{pH}$ value for straw fiber and has a significant impact on the straw fiberboards' bonding strength, with no clear improvement in bending strength of four treated types of straw fiberboards. They also concluded that treat with $\mathrm{CH}_{3} \mathrm{COOH}$ is optimum treatment for producing good quality of straw fiberboard. The chemical changes also contributed to the low bending and bonding strength of MDF. Li et al., [16] examined the chemical changes in the cell wall resulting from the hemicelluloses extraction and found make that acid treated fiber and UF resin less compatible. At the same time, acid treatment can lower the $\mathrm{pH}$ value of the treated fibers and lead to the self-condensation of UF resin and contribute to the reduction of IB strength.

It has been noted that the better adhesion properties can be improved by pre-treatment using varieties of chemicals such as sodium hydroxide $(\mathrm{NaOH})$, acid acetic $\left(\mathrm{CH}_{3} \mathrm{COOH}\right)$, sodium perchlorate ( $\mathrm{NaClO} 4)$, and others. It is believed that the correct selection of the chemical during pre-treatment will produce fiber with acceptance properties. Since the adhesion between the EFB fiber and the resin is an important element in the realization of the mechanical properties of the MDF, studies have focused on pre-treatment fibers to improve the properties of the panel. Thus, the main objective of this was to identify and assess the effects of $\mathrm{NaOH}$ and $\mathrm{CH}_{3} \mathrm{COOH}$ as treatment material at different concentrations in medium density fiberboard (MDF) manufacture. Mechanical properties of the MDF panel as a function of treatment and concentration were also evaluated.

\section{Methodology}

\subsection{Materials}

Oil palm EFB was obtained from the Sri Langat Oil Palm Mill located at Dengkil, Selangor, Malaysia with initial moisture content of $110 \%$. The EFB was then transported to Malaysian Palm Oil Board (MPOB) Pilot Plant and chipped using a drum chipper. 


\subsection{Pre-treatments and Refining of EFB}

The EFB then were treated with two types of chemicals: one being sodium hydroxide $(\mathrm{NaOH})$, while the other was acetic acid $\left(\mathrm{CH}_{3} \mathrm{COOH}\right)$ - tested at four different concentrations: $0.2,0.4,0.6$ and $0.8 \%$. The parameters selected for this study was based on findings and observations made in the previous study $[3,9,10]$. The EFB was soaked in a chemical solution at room temperature for a whole day, 24 hours. The treated EFB was initially washed with water to remove any impurities and air was then dried for 24 hours prior to the refining process.

\subsection{Refining of the EFB}

The treated EFB fiber were heated at $0.6 \mathrm{MPa}$ of refining pressure for 5 minutes followed by refined at refiner temperature of 150 to $170^{\circ} \mathrm{C}$ through the usage of a Sprout-Bauer (ANDRITZ) refiner, at an MDF pilot plant that was located at the MPOB/UKM Research Station. The moisture content was below $5 \%$ after the fibres were dried.

\subsection{Fibreboard Production}

Refined EFB fibers with MC of 3-4\% were blending with Urea-Formaldehyde (UF) resin with solid content of $64 \%$. The UF resin was sprayed onto the fibers using a rotary drum blender and the resinated fibers were formed into mats. The mats had to first go through a process of cold pressing with a pressure of $50 \mathrm{~kg} / \mathrm{cm}^{2}$ for an estimation of 3 minutes, which is subsequently followed by being hot pressed at pressure of $160 \mathrm{~kg} / \mathrm{cm}^{2}$ at $175{ }^{\circ} \mathrm{C}$ for 5 minutes. The target density of the board was $0.70 \mathrm{~g} / \mathrm{cm}^{3}$ with board dimensions of $300 \times 300 \times 12 \mathrm{~mm}$. The MDF panels were kept conditioning at $20 \pm 2{ }^{\circ} \mathrm{C}$ and $65 \%$ relative humidity in the conditioning room until reached balance moisture content.

\subsection{Mechanical Properties Evaluation}

The bending strength of the panel were conducted according to EN 622-5, 2006 using Zwick Universal Testing Machine with load of $10 \mathrm{kN}$, using crosshead speed of $3 \mathrm{~mm} / \mathrm{min}$ and span length of $240 \mathrm{~mm}$. Samples were glued to the metal blocks of a surface area of $50 \times 50 \mathrm{~mm}$ with a hot melt resin to be tested for IB. There is another heated metal block containing heated glue on the other side of the IB sample. The samples were then kept in the conditioning room 24 hours before the test. The crosshead speeds for all specimens were $3 \mathrm{~mm} / \mathrm{min}$. The data were statistically analyzed using Statistical Analysis System (SAS) software. Analysis of Variance (ANOVA) was used to examine the effects of treatment on the panel properties. Least Significant Difference (LSD) method was used for mean separation to further evaluate the effects of different treatments and concentrations, and the interaction between both parameters.

\section{Results}

The summary of ANOVA on the panel properties is summarized in Table 1. The effect of different treatments and concentrations on the MDF mechanical properties including modulus of rupture (MOR), modulus of elasticity (MOE) and internal bonding (IB) were determined. 


\section{Table 1}

Analysis of variance (ANOVA) on the MDF mechanical properties for differences EFB treatment effects

\begin{tabular}{lllll}
\hline Variables & d.f & p-value & & MOE \\
& & MOR & $* *$ & IB \\
\hline Treatment (T) & 2 & $* * * * *$ & n.s \\
Concentration (C) & 4 & n.s & $*$ & $* * *$ \\
Interaction $(T \times C)$ & 8 & $* * *$ & $* * *$ & . \\
\hline
\end{tabular}

Note: ${ }^{* *}$ : Significantly different at $\mathrm{p} \leq 0.01,{ }^{*}$ : Significantly different at $\mathrm{p} \leq 0.10$, ns: not significant

It was found that, high significant interactions $(p \leq 0.01)$ between treatment and concentration were observed for all panel mechanical properties. Between the two variables, treatment has more dominant effect $(p \leq 0.01$ ) on all mechanical properties of MDF. Compared to the concentration which has no effect on all mechanical properties.

\subsection{Bending Strength}

The MOR measures the maximum load that the composite panel can support and demonstrates the amount of stress required to cause failure, and the MOE measures the stiffness of the composite panel and demonstrates the ability to resist deflection. Figure 1 and Figure 2 show the value of the MOR and MOE of the EFB treated fiber panel. Treatment at 0.2 and $0.4 \%$ of $\mathrm{NaOH}$, the MOR and MOE of the panels were 15.5 and $1101 \mathrm{MPa}$, and 17.9 and $1297 \mathrm{MPa}$ respectively. Both properties were, however reduced to the range of 11.2 to $13.6 \mathrm{MPa}$ of MOR and 810 to $927 \mathrm{MPa}$ of MOE when the concentration has increased to 0.6 and $0.8 \%$. The MOR and MOE values decreased significantly when the $\mathrm{NaOH}$ concentration was increased from 0.4 to 0.6 and $0.8 \%$. Nevertheless, the panels produced from $\mathrm{CH}_{3} \mathrm{COOH}$ treated fibres had relatively higher bending strength values in both MOR and MOE than panels manufactured from $\mathrm{NaOH}$ treated fibres. The value of MOR increased from a range of 18.4 to $20.8 \mathrm{MPa}$, and the value of MOE increased from a range of 1291 to $1638 \mathrm{MPa}$ with increased concentration of $\mathrm{CH}_{3} \mathrm{COOH}$ from 0.2 to $0.8 \%$.

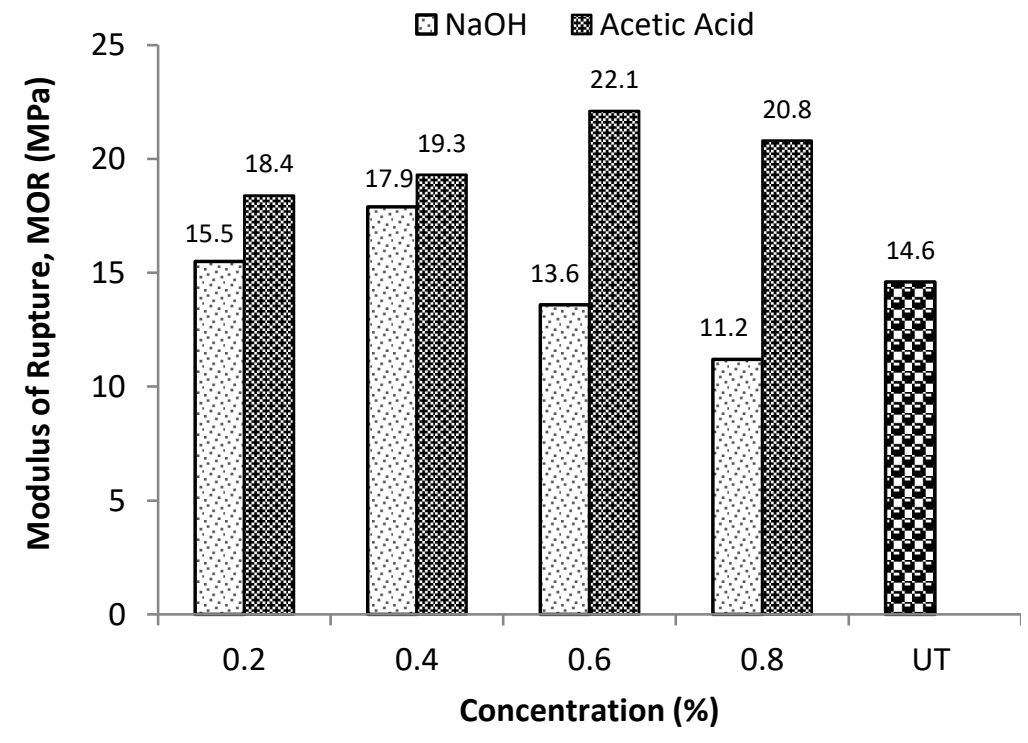

Fig. 1. The mean values of Modulus of Rupture (MOR) of MDF from treated empty fruit bunch (EFB) fibres 
Based on the approach of the Least Significant Difference (LSD) method, means figures that were subsequently followed by the same letters do not differ significantly, at $p \leq 0.05$. UT = Untreated fibres.

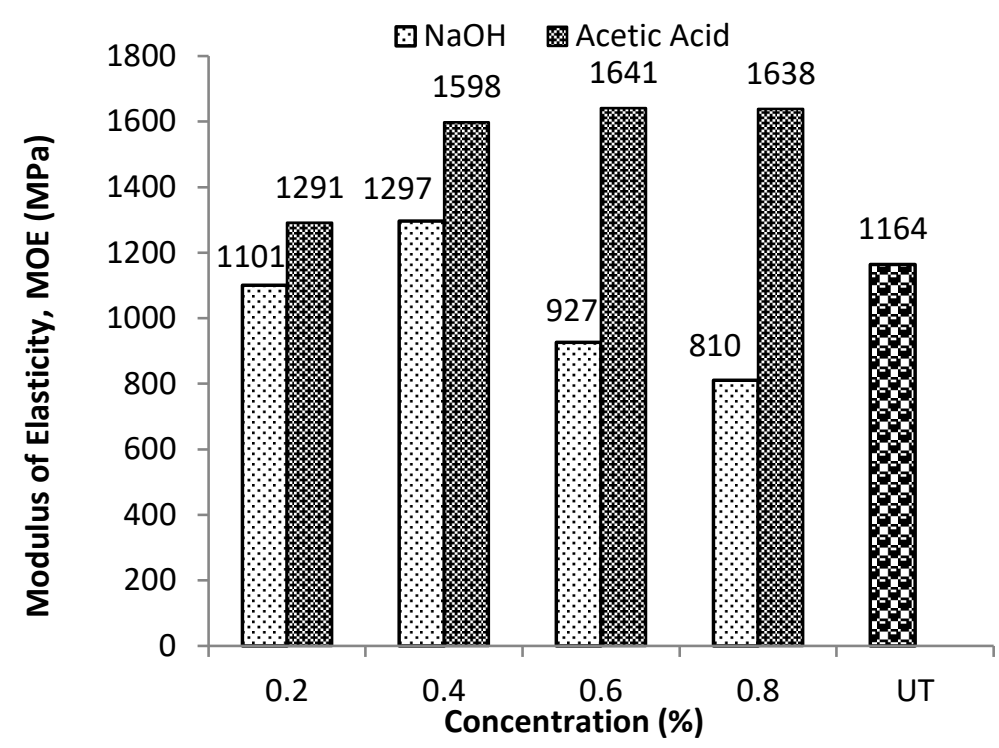

Fig. 2. The mean values of Modulus of Elasticity (MOE) of MDF from treated empty fruit bunch (EFB) fibres

Based on the approach of the Least Significant Difference (LSD) method, means figures that were subsequently followed by the same letters do not differ significantly, at $p \leq 0.05$. UT = Untreated fibers.

The results show that the MOR and MOE increased to 17.9 and $1297 \mathrm{MPa}$, respectively as the EFB fibers were treated with $\mathrm{NaOH}$ concentration from 0.2 to $0.4 \%$. Increased values are likely due to the removal of impurities, including residual oil and wax, on fiber producing EFB fibers with a more accessible surface. The removal of impurities can attribute to better wetting of the EFB treated fibers and UF. Nevertheless, as $\mathrm{NaOH}$ concentration was increased to $0.6 \%$ and $0.8 \%$, the results show a substantial decrease in the values of MOR and MOE. The reduction in bending strength is related to the formation of a fiber lump. Fiber lump formed as the result of excessive $\mathrm{NaOH}$ amount during the treatment, thereby increase $\mathrm{OH}$ concentration [12]. Consequently, the availability of cellulose makes the fiber much more flexible, thus results in the formation of fiber lumps [3,17]. During hot pressing, the lumps would be pressed into dense areas relative to the remainder of the MDF. This inhomogeneity generates excess internal stress, mostly in bending, and therefore lowers the MOR and MOE values of the panel. According to Ibrahim et al., [7], excessive treatments can degrade the molecular chains of lignocellulosic materials, specifically the cellulose. The drop in MOR and MOE is in agreement with earlier observation by Ndazi et al., [18] who obtained that at high concentration of $\mathrm{NaOH}$, the size of rice husks was reduced and non-uniform interface bonding in the panels occurred due to the increasing the surface area. Moreover, at high concentration of $\mathrm{NaOH}$, the physical and chemical degradation of EFB fibers occurred and caused deterioration of the fiber stiffness and strength.

Conversely, panels made from $\mathrm{CH}_{3} \mathrm{COOH}$ treated fibers, both MOR and MOE values increased as the concentration increased from 0.2 to $0.6 \%$. Mechanical properties of the panels were found to be influenced by the tensile strength of the fiber. Treatment at higher concentration of $\mathrm{CH}_{3} \mathrm{COOH}$ produced fibers with higher tensile strength due to the lots of cellulose content. Aji et al., [19] stated that the tensile strength of fiber increases with the increasing of cellulose content. This supported by 
Nishino et al., [20] who indicated that the crystal region gives the maximum value for the specimen modulus of panel. However, as the concentration of $\mathrm{CH}_{3} \mathrm{COOH}$ increases to $0.8 \%$, the MOR and MOE value decreases. This phenomenon could be related to the strong acid characteristic that can destroy the cellular fiber and reduce the tensile strength of the treated fiber. The higher level of hydrolysis at high levels of $\mathrm{CH}_{3} \mathrm{COOH}$ appears to have caused a decrease in the strength of the fiber, thus, leading to a reduction in the values of MOR.

\subsection{Internal Bonding (IB) Strength}

IB strength indicates the homogeneity of the fiber to the fiber adhesion and was related to the dimensional stability of the panels. Figure 3 provides the IB values of panels from $\mathrm{NaOH}$ and $\mathrm{CH}_{3} \mathrm{COOH}$ EFB treated fibres. As can be seen from the figure, the IB value of the samples increased with an increase in concentration in both treatments. However, following the treatment using $\mathrm{NaOH}$ it was observed that 0.6 and $0.8 \%$ concentration of $\mathrm{NaOH}$ had detrimental effect on the bonding properties of the fibres. The value of IB strength for the panel produced from $\mathrm{NaOH}$ treated fibre increased from 0.43 to $0.48 \mathrm{MPa}$ significantly when the concentration increased from 0.2 to $0.4 \%$ and the IB value decreased in the further concentration, whereas the panel produced from $\mathrm{CH}_{3} \mathrm{COOH}$ treated fibre showed an improvement in IB strength from 0.47 to $0.53 \mathrm{MPa}$ with the increment of $\mathrm{CH}_{3} \mathrm{COOH}$ concentration.

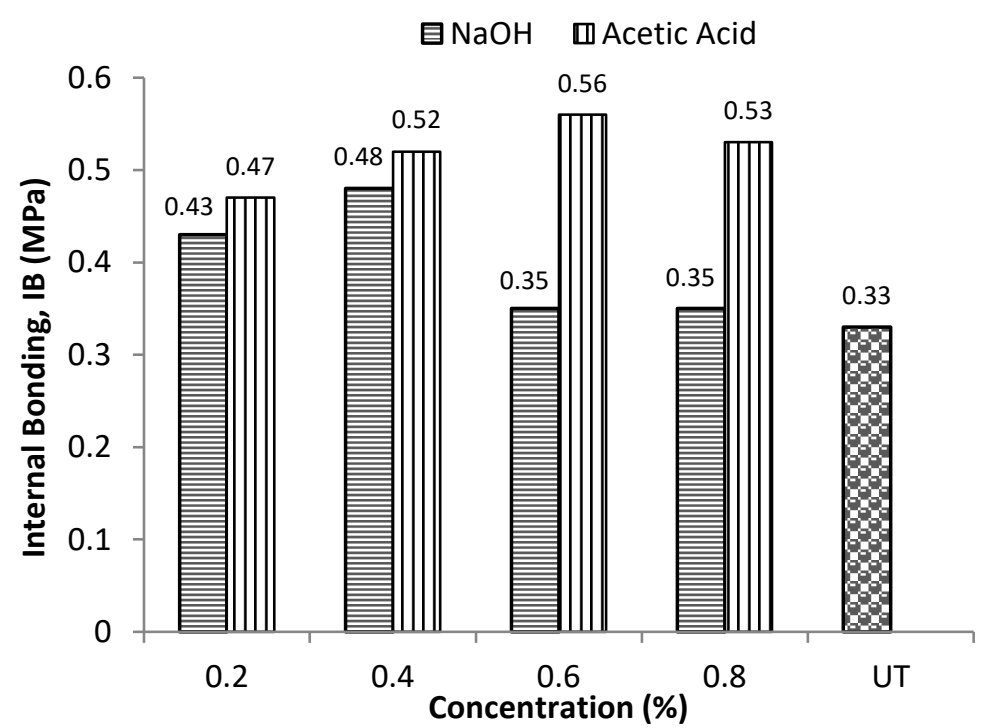

Fig. 3. The mean values of Internal Bonding (IB) of MDF from treated empty fruit bunch (EFB) fibres

Based on the approach of the Least Significant Difference (LSD) method, means figures that were subsequently followed by the same letters do not differ significantly, at $p \leq 0.05$. UT $=$ Untreated fibres.

The IB strength increase when $\mathrm{NaOH}$ concentration was increased from 0.2 to $0.4 \%$. The improvement of bonding is mainly due to the partial removal of oil and waxes on the surface of the fiber by $\mathrm{NaOH}$ treatment, thus providing better wetting properties of the surface and thus increasing the absorption of UF by the surface of the fiber. This surface may disrupt the efficiency of UF as a coupling agent by preventing penetration, thereby affecting the contact between the fibers and the adhesive resulting in a low IB value. This effect may ultimately increase the properties of the fiber adhesion, resulting in improved bonding properties for the panel. Previous researchers $[3,21,22]$ 
reported that $\mathrm{NaOH}$ treatment removed some oil, waxes, and other impurities from EFB fibers, and allows the resin to spread easily on the fiber surfaces.

However, the values of IB of the $\mathrm{NaOH}$ treated panels dropped significantly as the concentration of $\mathrm{NaOH}$ increased to 0.6 and $0.8 \%$. Decreasing IB strength may be associated with increasing $\mathrm{pH}$ values that will affect the rate of UF reaction during panel production [23]. The UF resin reaction is then triggered and propagated in an acidic condition that originates from the fibers themselves or from the addition of acid chemicals. Increased $\mathrm{pH}$ values have a profound effect on the formation of alkaline fibers that will negatively affect UF, an acid-based resin that requires the acidic environment to be cured. Fibers with different $\mathrm{pH}$ values will yield different resin curing times during hot pressing [23]. In general, UF resin mixed with fibers with high $\mathrm{pH}$ value will require more time to cure. The decreasing IB indicated that the hot-pressing time ( 5 minutes) used in this study accompanied with high $\mathrm{pH}$ fibers is insufficient to cure the resin, thus resulting in poor bond strength.

The results also indicated that treated fiber with $\mathrm{NaOH}$ at high concentration surface shows deposition of impurities and the existence of fiber lump. The presence of these substances on the surface of the fiber inhibits the ability of the UF resin to spread on the surface of the fiber and thus negatively affects the contact between the fiber and the resin and produces panels with poor bonding properties. Gillah et al., [24] stated that the resulting low IB values for panels were caused by the refined fibers with resin being poorly mixed, with samples failure occurring at the interface of fiber lumps.

\subsection{Acid Treatment}

Treatment of EFB fibers with $\mathrm{CH}_{3} \mathrm{COOH}$ prior to panel manufacturing has been found to significantly improve the properties of IB. From the finding, $\mathrm{CH}_{3} \mathrm{COOH}$ treated fibres with enough $\mathrm{CH}_{3} \mathrm{COOH}$ yield in relatively higher IB strength. The significant changes in the bonding effects of the panels in the treatment of $\mathrm{CH}_{3} \mathrm{COOH}$ can be attributed to the removal of residual oil in fibers. The presence of oil inhibits the rate of adhesive spread because this oil layer prevents the adhesive from distributing well on the surface of the fibre, creating poor adhesion between the fibre and the adhesive. Lee and Wang [25] reported that wax, oil and pectin on the fiber surface influenced the bonding properties of boards, due to the reason that these elements may form a thin film on the fiber surfaces, thus interrupt the fiber-UF bonding.

The oil content in the $\mathrm{CH}_{3} \mathrm{COOH}$ treated fibres is the main factor that contributed to the bonding properties. Higher IB values have been found to be associated with better fibre contact resulting from properly treated fibres, which may lead to the removal of certain materials, including wax, globular protrusions, oil and impurities from the surface of the fibres. The elimination of these substances leads to a more consistent distribution of the glue on the smooth surface of the fiber, resulting in further fiber-to-fiber contact being overlapped, thereby allowing stronger interlocking of the fiber adhesive and thus improving the bonding properties of the plate. A previous study by Nemli et al., [26] supported similar results by stating that if more contact is made within the fibre, this will increase the bonding of the fibres with improved resin efficiency during hot pressing.

The $\mathrm{pH}$ value of the fibre can be correlated with the good bonding ability of the generated panels. This result can be explained by the fact that good compatibility between fibre and UF resin can lead to the good distribution and curing of the UF matrix with the EFB fibres. Xing et al., [27] argued that the change in $\mathrm{pH}$ could affect UF curing and influence UF bonding. Because the UF resin is an acid-based adhesive, it needs an acidic environment to wet the fibres in order to achieve adequate bonding and to develop bonds. Xing et al., [28] concluded that the strength of the IB could be affected by a change in the $\mathrm{pH}$ values of the fibers which would result in different resin curing 
times during hot pressure. Fiber acidity has played a vital role in the gel time and curing behavior of the resins and affects the performance of the MDF panels. There are number of studies that have assessed the influence of the fibre acidity on the performance of MDF panels $[3,23,24,29]$. Slight reduction of properties at $0.8 \%$ of $\mathrm{CH}_{3} \mathrm{COOH}$ can be attributed to pre-curing of UF. More highly acidic fibers are expected to result in higher degrees of pre-curing during panel processing and to create poor fiber-to-fiber bonding. One study by Li et al., [16] also reported similar finding where the IB strength of acid treated MDF reduced because low $\mathrm{pH}$ lead to self-condensation of UF resin.

\section{Conclusions}

The study found that the state of treatment, which requires various types of chemical and concentrations, influences the properties of the plate. Both pre-treatments are said to have a much more pronounced effect on the properties of the panel compared to the concentration of the material. Treated fiber with $\mathrm{CH}_{3} \mathrm{COOH}$ produced panel with better strength and bonding properties compared to alkaline treatment. Alkaline treatment at concentration higher than $0.6 \%$ produced samples with relatively lower strength and IB properties. The MOR, MOE and IB properties of the panels treated with $\mathrm{NaOH}$ were found to markedly reduce at more severe treatment. The findings of the current study also suggest that the condition of treatment was crucial to the production of superior MDF properties. The optimum properties of MOR, MOR and IB were $22.1 \mathrm{MPa}, 1641 \mathrm{MPa}$ and $0.56 \%$, respectively at $0.6 \%$ of $\mathrm{CH}_{3} \mathrm{COOH}$ resulted in acceptable mechanical properties according to the EN 622-5 (Requirement for Ultra-light MDF board).

\section{Acknowledgement}

This research was supported by Biomass Technology Unit, Malaysian Palm Oil Board (MPOB), Faculty of Applied Sciences, Universiti Teknologi MARA and Institute of Tropical Forestry and Forest Products (INTROP), Universiti Putra Malaysia.

\section{References}

[1] Hassan, Azman, Arshad Adam Salema, Farid Nasir Ani, and Aznizam Abu Bakar. "A review on oil palm empty fruit bunch fiber-reinforced polymer composite materials." Polymer Composites 31, no. 12 (2010): 2079-2101. https://doi.org/10.1002/pc.21006

[2] Zaidon, A., A. M. Norhairul Nizam, M. Y. Nor, F. Abood, M. T. Paridah, M. Y. Nor Yuziah, and H. Jalaluddin. "Properties of particleboard made from pretreated particles of rubberwood, EFB and rubberwood-EFB blend." Journal of Applied Sciences 7, no. 8 (2007): 1145-1151. https://doi.org/10.3923/jas.2007.1145.1151

[3] Norul, Izani, M. T. Paridah, A. A. Astimar, Nor Mohd, and U. M. K. Anwar. "Mechanical and dimensional stability properties of medium-density fibreboard produced from treated oil palm empty fruit bunch." Journal of Applied Sciences 12, no. 6 (2012): 561-567.

https://doi.org/10.3923/jas.2012.561.567

[4] Sahari, J., M. N. Nuratiqah, and M. M. Rao. "Developing and prototyping of empty fruit bunch high density board." Journal of Advance Research Design 3, no. 1 (2014): 1-8.

[5] Shuit, Siew Hoong, Kok Tat Tan, Keat Teong Lee, and A. H. Kamaruddin. "Oil palm biomass as a sustainable energy source: A Malaysian case study." Energy 34, no. 9 (2009): 1225-1235. https://doi.org/10.1016/i.energy.2009.05.008

[6] Senawi, Rosman, Sakinah Mohd Alauddin, Ruzitah Mohd Saleh, and Mohammed Iqbal Shueb. "Polylactic acid/empty fruit bunch fiber biocomposite: Influence of alkaline and silane treatment on the mechanical properties." International Journal of Bioscience, Biochemistry and Bioinformatics 3, no. 1 (2013): 59-61. https://doi.org/10.7763/IJBBB.2013.V3.164

[7] Ibrahim, Siti Munirah, Haji Badri Khairiah, and Hassan Osman. "A study on glycerolysis of oil palm empty fruit bunch fiber." Sains Malaysiana 41, no. 12 (2012): 1579-1585. 
[8] Khalil, H. P. S. Abdul, MR Nurul Fazita, and C. K. Abdullah. "Hybridized biocomposites from agro-wastes: Mechanical, physical and thermal characterization." Journal of Polymers and the Environment 19, no. 1 (2011): 49-58. https://doi.org/10.1007/s10924-010-0245-5

[9] Arif, Muhamad F., Puteri SM Megat-Yusoff, and Faiz Ahmad. "Effects of chemical treatment on oil palm empty fruit bunch reinforced high density polyethylene composites." Journal of Reinforced Plastics and Composites 29, no. 14 (2010): 2105-2118. https://doi.org/10.1177/0731684409348976

[10] Ridzuan, Ramli, S. Shaler, and Ariff Jamaludin Mohd. "Microstructure of medium density fibreboard from oil palm empty fruit bunch fibre." Journal of Oil Palm Research 14, no. 1 (2002): 35-44.

[11] Ibrahim, Zawawi, Mansur Ahmad, Astimar Abdul Aziz, Ridzuan Ramli, Kamarudin Hassan, and Aisyah Humaira Alias. "Properties of Chemically Treated Oil Palm Empty Fruit Bunch (EFB) Fibres." Journal of Advanced Research in Fluid Mechanics and Thermal Sciences 57, no. 1 (2019): 57-68.

[12] Sreekala, M. S., M. G. Kumaran, and Sabu Thomas. "Oil palm fibers: Morphology, chemical composition, surface modification, and mechanical properties." Journal of Applied Polymer Science 66, no. 5 (1997): 821-835. https://doi.org/10.1002/(SICI)1097-4628(19971031)66:5<821::AID-APP2>3.0.CO;2-X

[13] Shahriarinour, Mahdi, Mohd Noor Abdul Wahab, Arbakariya Bin Ariff, Shuhaimi Mustafa, and Rosfarizan Mohamad. "Effect of various pretreatments of oil palm empty fruit bunch fibres for subsequent use as substrate on the performance of cellulase production by Aspergillus terreus." BioResources 6, no. 1 (2011): 291-307.

[14] Khalil, H. P. S. Abdul, A. M. Issam, MT Ahmad Shakri, R. Suriani, and A. Y. Awang. "Conventional agro-composites from chemically modified fibres." Industrial Crops and Products 26, no. 3 (2007): 315-323. https://doi.org/10.1016/i.indcrop.2007.03.010

[15] Pan, Mingzhu, Hailan Lian, and Dingguo Zhou. "Chemical characteristics of straw fiber and properties of straw fiberboard with different pretreatments." Frontiers of Forestry in China 2, no. 2 (2007): 237-240. https://doi.org/10.1007/s11461-007-0039-7

[16] Li, Xianjun, Zhiyong Cai, Eric Horn, and Jerrold E. Winandy. "Effect of oxalic acid pretreatment of wood chips on manufacturing medium-density fiberboard." Holzforschung 65, no. 5 (2011): 737-741. https://doi.org/10.1515/hf.2011.060

[17] Browning, Bertie Lee. Methods of Wood Chemistry. Vol. 2. Wiley, New York, 1967.

[18] Ndazi, Bwire S., Sigbritt Karlsson, J. V. Tesha, and C. W. Nyahumwa. "Chemical and physical modifications of rice husks for use as composite panels." Composites Part A: Applied Science and Manufacturing 38, no. 3 (2007): $925-$ 935. https://doi.org/10.1016/i.compositesa.2006.07.004

[19] Aji, I. S., S. M. Sapuan, E. S. Zainudin, and K. Abdan. "Kenaf fibres as reinforcement for polymeric composites: a review." International Journal of Mechanical and Materials Engineering 4, no. 3 (2009): 239-248.

[20] Nishino, Takashi, Ikuyo Matsuda, and Koichi Hirao. "All-Cellulose Composite." Macromolecules 37, no. 20 (2004): 7683-7687. https://doi.org/10.1021/ma049300h

[21] Islam, Md Saiful, Sinin Hamdan, I. Jusoh, Md Rezaur Rahman, and Abu Saleh Ahmed. "The effect of alkali pretreatment on mechanical and morphological properties of tropical wood polymer composites." Materials \& Design 33 (2012): 419-424. https://doi.org/10.1016/i.matdes.2011.04.044

[22] Suradi, S. S., R. M. Yunus, M. D. H. Beg, and Z. A. M. Yusof. "Influence pre-treatment on the properties of lignocellulose based biocomposite." In National Conference on Postgraduate Research, pp. 67-78. 2009.

[23] Xing, Cheng, James Deng, and S. Y. Zhang. "Effect of thermo-mechanical refining on properties of MDF made from black spruce bark." Wood Science and Technology 41, no. 4 (2007): 329-338. https://doi.org/10.1007/s00226-006-0108-3

[24] Gillah, P. R., M. A. Irle, and S. A. Amartey. "Development and production of laboratory scale novel MDF panels from composite and nonwoven mattresses of sisal and wood fibre mixtures." Holz als Roh-und Werkstoff 58, no. 5 (2000): 324-330. https://doi.org/10.1007/s001070050438

[25] Lee, S. H., and S. Wang. "Characterization of interfacial properties between cellulose fiber and thermoplastic by AFM and nanoindentation." In The 23th ACS National Meeting, Division of Industrial and Engineering Chemistry, Washington, DC. 2005.

[26] Nemli, Gökay, Ismail Aydın, and Emir Zekoviç. "Evaluation of some of the properties of particleboard as function of manufacturing parameters." Materials \& Design 28, no. 4 (2007): 1169-1176. https://doi.org/10.1016/i.matdes.2006.01.015 
[27] Xing, Cheng, S. Y. Zhang, and James Deng. "Effect of wood acidity and catalyst on UF resin gel time." Holzforschung 58, no. 4 (2004): 408-412. https://doi.org/10.1515/HF.2004.061

[28] Xing, Cheng, James Deng, S. Y. Zhang, Bernard Riedl, and Alain Cloutier. "Properties of MDF from black spruce tops as affected by thermomechanical refining conditions." Holz als Roh-und Werkstoff 64, no. 6 (2006): 507-512. https://doi.org/10.1007/s00107-006-0129-5

[29] Hernández, Vicente. "Radiata pine pH and buffering capacity: Effect of age and location in the stem." Maderas. Ciencia y Tecnología 15, no. 1 (2013): 73-78. https://doi.org/10.4067/S0718-221X2013005000007 